OPEN ACCESS

Edited by:

Cathal Gurrin

Dublin City University, Ireland

Reviewed by:

Laszlo Balkanyi,

University of Pannonia, Hungary

Corinne Alberti,

Université de Paris, France

*Correspondence:

Michaela Coenen

coenen@ibe.med.uni-muenchen.de

Specialty section:

This article was submitted to

Digital Public Health,

a section of the journal

Frontiers in Public Health

Received: 21 May 2021

Accepted: 12 October 2021

Published: 16 November 2021

Citation:

Schroeer $C$, Voss S, Jung-Sievers $C$ and Coenen M (2021) Digital Formats for Community Participation in Health Promotion and Prevention Activities: A

\section{Digital Formats for Community Participation in Health Promotion and Prevention Activities: A Scoping Review}

\author{
Claudia Schroeer ${ }^{1,2}$, Stephan Voss ${ }^{1,2}$, Caroline Jung-Sievers ${ }^{1,2}$ and Michaela Coenen ${ }^{1,2 *}$ \\ ${ }^{1}$ Chair of Public Health and Health Services Research, Institute for Medical Information Processing, Biometry, and \\ Epidemiology - IBE, LMU Munich, Munich, Germany, ${ }^{2}$ Pettenkofer School of Public Health, Munich, Germany
}

Objectives: Digital technologies in public health are primarily used in medical settings and mostly on an individual and passive way of use. There are research gaps on digital media facilitating participation, empowerment, community engagement, and participatory research in community settings. This scoping review aims to map existing literature on digital formats that enable participation in the field of health promotion and prevention in community settings.

Design: The databases Medline, EMBASE, and PsycINFO were used to identify studies published from 2010 up to date (date of literature search) onward that used digital formats in all or in the main sequences of the process to enable high levels of participation in health promotion and prevention activities in community settings.

Results: This review identified nine out of 11 included studies relevant to the research question. We found five studies that applied qualitative participatory research, two studies on peer support and one study each on empowerment and crowdsourcing. The digital technologies used varied widely and included social media platforms, bulletin boards, online forum webpages, and customized web providers and programs. Most studies mentioned anonymity, flexibility, and convenience as benefits of digital interventions. Some papers reported limitations such as difficulties by interpreting written-only data or the possibility of selection bias due to the digital divide.

Conclusion: This scoping review identified only few studies relevant to our objective, indicating an existing gap in research on this topic. Digital formats were found to be particularly suitable for purposes where anonymity and flexibility are beneficial, such as for online peer exchange and peer support programs.

Keywords: health promotion, digitalization, public health, participation, community, empowerment

\section{INTRODUCTION}

The Ottawa Charta and the Alma Ata Declaration defined community participation as a basic element and key principle for health-promoting activities and programs $(1,2)$. The Ottawa Charta for Health Promotion was published at the conclusion of the first International Conference on Health Promotion by the World Health Organization (WHO) in Ottawa on November 21, 1986. 
It is considered one of the most important follow-up documents to the Declaration of Alma-Ata (1978), in which WHO declared basic health care and health promotion to be a fundamental human right. Since these declarations, community participation has become an increasing subject of interest in research and practice (3). Involving members of a community in health promotion may increase the effectiveness of public health interventions and reduce health inequalities for socially disadvantaged groups (4). Participation processes can strengthen social networks that reinforce healthy behaviors and reduce feelings of isolation (5). On an individual level, participation in decision-making processes increase the experience of selfefficacy. Furthermore, participation may initiate a process of empowerment, which enables communities to shape their environment, health, and lives according to their own interests (6). Community-based participatory strategies are based on the assumption that community members are experts of their own lives and thus know best how to improve the health of their community (6).

Communities can be defined as geographic entities ranging from neighborhoods to towns or cities, as well as larger geographic areas (7). Irrespective of geographic boundaries, a community can also be defined by common identity "based on race, gender, religious belief, sexual orientation, or a community-based organization united for a particular cause" (8). Participation was first categorized in Arnstein's ladder of citizen participation. It consists of eight rungs describing a range from non-participation to tokenism to the degree of citizen power (9). This idea has been further developed and adapted in the stage model of participation by Wright et al. (10). They define true participation as involving community members in the decision-making process, including the level in which community members are encouraged to make decisions, have partial decision-making authority, or have decision-making power (11). Below these stages, there are preliminary stages of participation, such as consultation like surveys, or stages that are not considered as participation, such as instruction. Beyond the level of participation goes empowerment by teaching participants necessary skills to initiate and carry out measures in a selforganized manner (12).

Advancing digitalization offers opportunities to exploit new possibilities in the implementation of health promotion and prevention programs (13). Many digital technologies, specifically devices such as computers, mobile phones, and tablets, are already accessible to a wide range of people of all ages and continue to evolve. A review by Clar et al. (14) on existing systematic reviews about the use of digital methods in public health found a wide variety of examples for digital approaches in the public health sector such as eHealth services, social marketing campaigns, apps, video games, telephone

\footnotetext{
Abbreviations: COVID-19, Coronavirus disease 19; FB, Facebook; GBMSM, Gay, bisexual, and other men who have sex with men; GBQ, Gay, bisexual, and queer; HIV, Human immunodeficiency virus; LGBTQ, Lesbian, gay, bisexual, transgender, queer; MSM, Men who have sex with men; WMD, Wheeled mobility devices.
}

interventions, online photovoice, online discussion forums, virtual communities, or online collaborative writing applications. The review found that digital technologies were primarily used in medical settings and mostly in an individual and passive manner. Identified research gaps were digital media facilitating participation, empowerment, community engagement, and participatory research in community settings.

To our best knowledge, there is no review identifying existing studies on digital formats for community participation, irrespective of a specific group or a specific type of community participation. For this reason, we conducted a scoping review to systematically map the research in this area on a broader level and identify core concepts.

This scoping review aims to map existing literature on digital formats that enable participation in the field of health promotion and prevention in community settings to provide a better and more comprehensive understanding of the research area. This review will focus only on interventions with a true level of participation according stage model of participation by Wright et al., meaning that participants had at least to be involved in the decision-making process, and interventions that follow a digital approach at all stages of the participative elements. Specific aims are to describe (1) the participatory elements that were used in the interventions, (2) how the digital formats were used to conduct health promotion and prevention activities ensuring participatory approaches, and (3) benefits and limitations mentioned in relation to the digital format.

\section{METHODS}

We conducted a scoping review to identify existing literature on digital formats that enable participation in the field of health promotion and prevention in community settings. The aim of a scoping review is to map existing literature on a specific topic and to identify characteristics and concepts behind it (15). In contrast to a systematic review, the focus is not on the synthesis of results on a specific question, e.g., the effect of an intervention, but on providing an overview and a description of the field of research. As another goal is to identify the range of evidence on the topic, different study designs may be included and a formal assessment of the methodological quality of the included studies is usually not performed (16).

This scoping review was based on the framework of Arksey and O'Malley (17) and incorporated suggestions for improvement from Levac et al. (18), Daudt et al. (19) and the Joanna Briggs Institute (20). Additionally, the preferred reporting items of the PRISMA checklist for scoping reviews (PRISMAScR) (21) were taken into account.

The following steps were conducted:

Step 1: Identifying the research question

Step 2: Identifying relevant studies

Step 3: Study selection

Step 4: Charting data

Step 5: Collating, summarizing and reporting results 
TABLE 1 | Inclusion and exclusion criteria.

\begin{tabular}{|c|c|c|}
\hline Category & Inclusion criteria & Exclusion criteria \\
\hline Population & $\begin{array}{l}\text { Members of a community, including geographically defined } \\
\text { communities, communities connected through common interests } \\
\text { or lifestyles or virtual communities }\end{array}$ & $\begin{array}{l}\text { Institutional settings (e.g., health care settings, school settings, or } \\
\text { occupational settings), clinical populations }\end{array}$ \\
\hline Concept & $\begin{array}{l}\text { Interventions or research methods that use digital formats in all, or } \\
\text { in the main sequences of the participatory process } \\
\text { Participation is defined as level 6-9 of the stage model of } \\
\text { participation by Wright (10) }\end{array}$ & $\begin{array}{l}\text { Interventions or research methods that } \\
\text { - use analogous formats in all, or in the main sequences of the } \\
\text { participatory process } \\
\text { - only allow participation under level } 6 \text { of the stage model of } \\
\text { participation by Wright, Unger and Block (10) }\end{array}$ \\
\hline Context & $\begin{array}{l}\text { All actions and programs relating to health promotion or health } \\
\text { prevention }\end{array}$ & $\begin{array}{l}\text { Actions and programs not related to health promotion or health } \\
\text { prevention }\end{array}$ \\
\hline Study design & Any empirical study design & $\begin{array}{l}\text { - Non-empirical studies (e.g., commentaries, letters, editorials, } \\
\text { recommendations, guidelines or overviews) } \\
\text { - Reviews or meta-analyses }\end{array}$ \\
\hline
\end{tabular}

Arksey and O'Malley suggest an optional Step 6 where practitioners and consumers can be consulted (17). This step was not performed in this review.

A protocol was developed a priori by the author team, following the same guidelines as described in this scoping review. The final protocol was registered with the Open Science Framework on February 21, 2021 (https://osf.io/v9jfc/).

\section{Step 1: Identifying the Research Question}

This scoping review was guided by the question: What kind of literature does already exist on digital formats that enable participation in the field of health promotion and prevention in community settings? Specific questions were: (1) Which participatory elements were used in the intervention? (2) How were digital formats used to conduct health promotion and prevention activities ensuring a participatory approach? (3) What benefits and limitations were mentioned related to the digital format?

We focused on the participation levels six to nine, according to the stage model of participation by Wright et al. (10). It defines true participation as participants being involved in the decision-making process or reaching a level of self-management. Furthermore, we were looking for an end-to-end digital approach that would be maintained throughout all or most sequences of the participation process, so that it would be feasible even in times of contact restrictions, as with the coronavirus pandemic.

\section{Step 2: Identifying Relevant Studies}

Literature searches were conducted in the databases Medline, EMBASE, and PsycINFO. The search strategy for the database search included database-controlled vocabulary and additional keywords, using truncations to search by title and abstract. The search strategy was identical for all three databases, adapted to the respective subheadings of the database and contained the following terms: communit* OR municipal* OR citi* OR city OR local OR neighborhood OR rural OR urban AND community participation OR participatory research OR participat* OR empower* OR involve* OR engage* OR partnership AND internet OR mobile applications OR social media OR smartphone OR mobile OR online OR digital OR photo* OR video*
AND health promotion OR public health OR prevention OR health education.

Given the rapidly changing technological developments over the last decade, the search was limited to publications from 2010 to current studies (up to date when search was performed: 11/13/2020). Only studies in English were included.

Hand searches were additionally performed from the reference list of relevant reviews identified during the title and abstract screening to search for literature that may not have been captured by the databases used. After the search, duplicates were removed in the EndNote citation management software.

\section{Step 3: Study Selection}

The third stage of Arksey and O'Malley's framework aims to identify the studies to be included in the scoping review. To maintain clear congruence between title, objectives, and research question, we based the inclusion and exclusion criteria on a PCC framework, consisting of the categories: population, concept, and context. "Study design" was added as an additional category (20).

We searched for members of a community, including geographically defined communities, communities connected through common interests or lifestyles or virtual communities. We focused on intervention or research concepts that used digital formats in all, or in the main sequences of the process for enabling participation or empowerment in the context of health promotion or prevention. Any empirical study designs except reviews or meta-analysis were included. The inclusion and exclusion criteria are shown in Table $\mathbf{1}$.

An iterative team approach was used for the screening process, which was conducted in two phases: first a title and abstract screening and second a full text screening with all included studies from the first phase. Prior to the initial title and abstract screening, an iterative process was used to screen the first 100 citations and discussed by the research team (MC, CJS, CS, SV) until inclusion and exclusion criteria were sufficiently specified. For the screening of records, one author (CS) screened $100 \%$ of the citations. The other authors divided $50 \%$ of the citations among each other, resulting in half of the records being double-screened independently. For the screening process, the web-based literature management program Rayyan was used. 
Conflicting reviewer decisions whether a study met the inclusion criteria were discussed and resolved in the team.

In the following full-text screening, a similar approach was used, resulting in $100 \%$ of the records being doublescreened independently. Again, all conflicting classifications were discussed and resolved within the team. To ensure that no articles were missing, reference lists of relevant reviews were screened by the first author by title and abstract, and in full-text where appropriate.

The selection process is illustrated by a PRISMA flow chart displaying the results of the screening steps.

\section{Step 4: Charting Data}

In the fourth stage of the scoping review framework, data was extracted from the included studies using an Excel spreadsheet. Following the recommendations from Levac et al. (18), the data extraction framework was developed collaboratively by the research team and iteratively updated. Four of the included studies were extracted independently by two authors and then discussed to test the coherence of the framework.

The extraction items where categorized into general information and specific information. The extracted data of the general information section were author, title, journal, year, country, health topic, study type, objectives, population (age, sex, characteristics, total number, setting), type and description of intervention, recruitment methods, data collection, sample size, analysis method, and findings.

The data extracted for the specific information section were type of digital elements and further detailed description of these elements, type of participatory activities and further description (such as level of participation) and benefits, limitations and conclusions related to the use of the digital formats.

\section{Step 5: Collating, Summarizing, and Reporting Results}

The results were collated and summarized based on relevance to the research questions and reported in three tables. The first and second table focus on general information about each study, with the first table providing preliminary information and the second table presenting details about the methodology and results. The third table focuses on answering the three specific research questions. It contains information about the interventions related to the participatory aspect, the digital format, and the experiences made with it. The presented tabular results are accompanied by a narrative summary.

\section{RESULTS}

A total of 5,384 articles were found through database searching. After duplicates were removed in Endnote, 3,735 articles remained for title and abstract screening. The reference lists of eight relevant reviews (22-29) identified in the title and abstract screening were additionally screened, but no priorly unknown relevant study was found. From this initial screening phase, 85 articles were included in the full-text screening. Eleven studies were finally identified that met our inclusion criteria. The most common reasons for exclusion in the full-text screening were "no access to full text" ( $n=28)$, mostly because only abstracts were available, and "wrong concept in relation to the digital format" $(n=29)$. Of the included 11 studies, three reported on the same intervention (30-32). The process of study selection is shown in the PRISMA flow chart (Figure 1) (33).

\section{Characteristics of Included Studies}

Table 2 provides general information on the 11 included studies on publication year, country, study type, health topic addressed, and the study objectives.

The included studies were published between 2010 and 2018 . Seven studies were from the USA $(30-32,34,37,39,41)$, noting that three studies were from the same research group, two were from Canada $(38,40)$, one from Australia (35), and one from Switzerland (36). Most studies $(n=6)$ followed a qualitative study design $(34-38,41)$, two were feasibility studies $(39,40)$, and the three studies from Young et al. were randomized controlled trials (30-32). Various public health topics were covered in the studies, such as breastfeeding (35), wheeled mobility devices (38), violence prevention (40), and health promotion in informal communities (39). The most common topic was HIV prevention, which was addressed in five of nine unique studies (30, 34, 36, 37, 41). The study objectives of the qualitative studies were all related to exploring the perspectives of the participants and therefore gaining a deeper understanding of the topic under research. The feasibility studies described the envisaged aims of their project and the RCT studies intended to measure the effectiveness of the intervention compared to a control group.

Table 3 presents general information of the 11 included studies regarding the target population and community setting, the data collection sources, the analysis methods, information on the participants of the sample and the main results.

The target population were adolescents or young adults in three studies $(34,36,41)$, adults aged 18 years or older in six studies (30-32, 37-39) and adolescents and adults in one study (40). One study did not specify its target population (35). All studies focused on community settings defined by common identity. Four of the nine unique studies additionally searched for a geographic community setting by looking for residents of a specific city $(30,38-40)$. The remaining studies had no specific geographic setting or only a widely defined one. One study targeted virtual communities (35).

Of the six qualitative studies, four collected data using online focus groups $(35,37,38,41)$ and two via written discussions from online forums $(34,36)$. One study conducted in-depth interviews in addition to focus groups (35). Three of these studies performed content analyses $(34,37,38)$ and three conducted thematic analyses $(35,36,41)$. Snider et al. (40) used a concept mapping software for collecting the data and performed a cluster analysis. Rothpletz-Puglia et al. (39) used various sources for data collection, such as self-reported activity logs and participant questionnaires, and applied a mixed methods approach. Young's studies also used multiple data sources, with baseline and followup surveys in each study, and conducted a mix of quantitative analysis methods (30-32).

The number of participants in the focus group studies varied between eight and 79 participants. The crowdsourcing project 


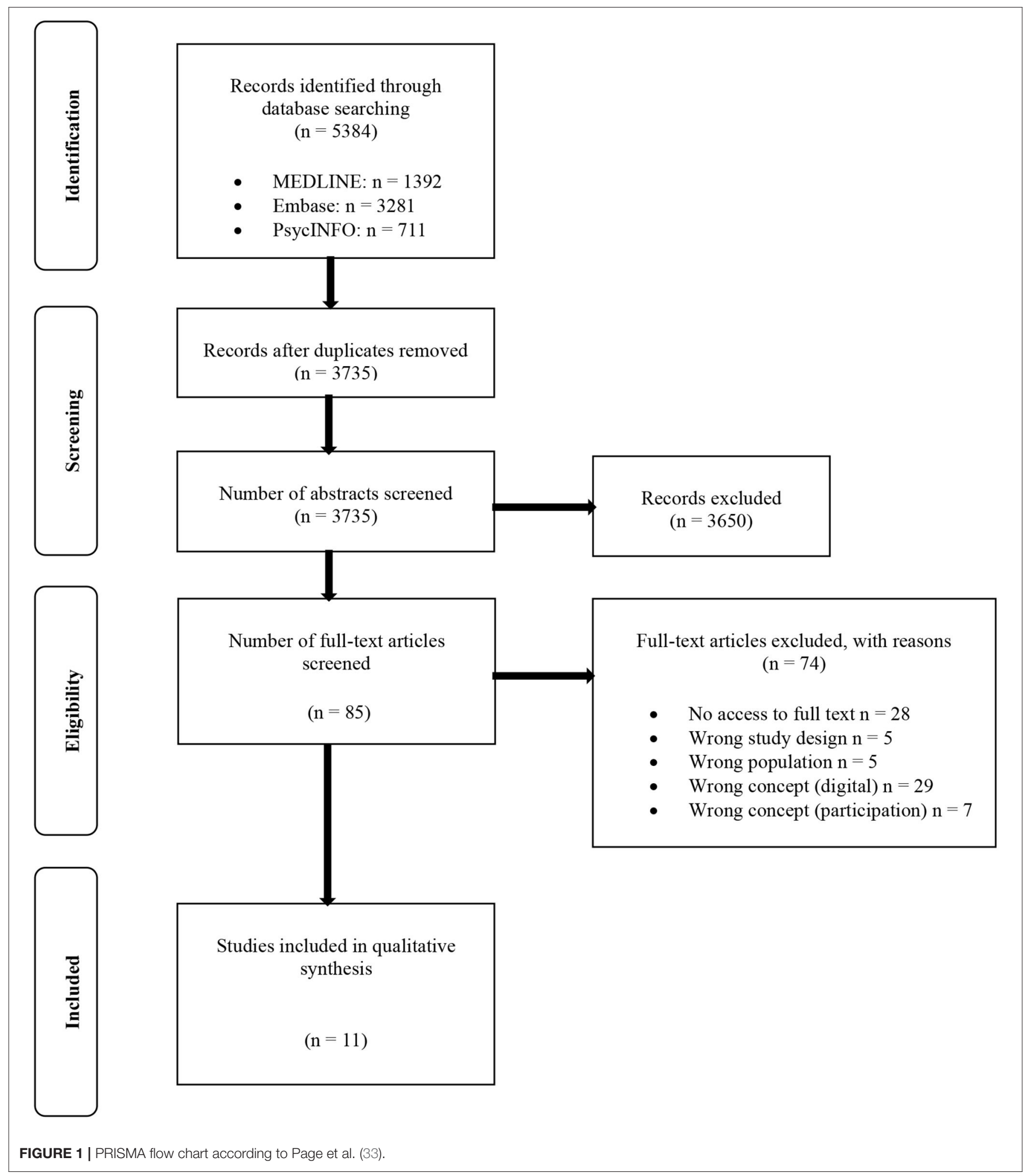

involved a total of 5,102 participants (36) and Snider's (40) concept mapping project a total of 278. Two studies by Young et al. reported the same sample $(31,32)$. These had a total number of 105 participants. The other study sample had a total number of 498 participants (30). All studies that conducted content or thematic analysis reported a deeper understanding regarding their study objectives. The two studies testing feasibility were able to confirm and reported a successful implementation and 
TABLE 2 | General information about included studies.

\begin{tabular}{|c|c|c|c|c|c|}
\hline First author & Year & Country & Study type & Health topic & Objectives \\
\hline Barry et al. (34) & 2018 & USA & $\begin{array}{l}\text { Qualitative study, } \\
\text { based on RCT }\end{array}$ & HIV prevention & $\begin{array}{l}\text { To understand how resilience processes are shared among young } \\
\text { Black GBMSM. }\end{array}$ \\
\hline Bridges (35) & 2016 & Australia & Qualitative study & Breastfeeding support & $\begin{array}{l}\text { To advance understanding of the experiences of mothers using } \\
\text { closed Facebook groups for breastfeeding support. }\end{array}$ \\
\hline $\begin{array}{l}\text { Hildebrand et al. } \\
\text { (36) }\end{array}$ & 2013 & Switzerland & Qualitative study & HIV prevention & $\begin{array}{l}\text { To present a focused thematic analysis of a sub-section of the } \\
\text { views expressed in the online and offline forums. }\end{array}$ \\
\hline lantaffi et al. (37) & 2015 & USA & Qualitative study & HIV prevention & $\begin{array}{l}\text { To examine the acceptable level of sexual explicitness in HIV } \\
\text { prevention advertisements. }\end{array}$ \\
\hline $\begin{array}{l}\text { Ripat and } \\
\text { Colatruglio (38) }\end{array}$ & 2016 & Canada & Qualitative study & $\begin{array}{l}\text { Wheeled mobility } \\
\text { devices }\end{array}$ & $\begin{array}{l}\text { To gain understanding of what people who use wheeled mobility } \\
\text { devices identify as environmental barriers to community } \\
\text { participation in cold weather climates. }\end{array}$ \\
\hline $\begin{array}{l}\text { Rothpletz-Puglia } \\
\text { et al. (39) }\end{array}$ & 2013 & USA & Feasibility study & Health promotion & $\begin{array}{l}\text { To offer opportunity and support for women at risk for or living with } \\
\text { HIV to identify, create, and provide health promotion messaging } \\
\text { within their informal personal networks. }\end{array}$ \\
\hline Snider et al. (40) & 2010 & Canada & Feasibility study & Violence prevention & $\begin{array}{l}\text { To engage youths, parents, and community workers in } \\
\text { conceptualizing a hospital-based violence prevention intervention } \\
\text { and to identify outcomes relevant to the community. }\end{array}$ \\
\hline Ybarra et al. (41) & 2014 & USA & Qualitative study & HIV prevention & $\begin{array}{l}\text { To examine self-reported behavioral and attitudinal changes } \\
\text { among GBQ adolescent males who took part in online focus } \\
\text { groups. }\end{array}$ \\
\hline Young et al. (30) & 2015 & USA & $\begin{array}{l}\text { Cluster randomized } \\
\text { controlled trial }\end{array}$ & HIV prevention & $\begin{array}{l}\text { To examine the efficacy of using the HOPE social media } \\
\text { intervention to increase HIV testing among MSM in Peru. }\end{array}$ \\
\hline Young et al. (31) & 2014 & USA & $\begin{array}{l}\text { Randomized controlled } \\
\text { trial }\end{array}$ & HIV prevention & $\begin{array}{l}\text { To assess whether changes in network growth are associated with } \\
\text { increased HIV prevention and testing behaviors. }\end{array}$ \\
\hline Young et al. (32) & 2013 & USA & $\begin{array}{l}\text { Cluster randomized } \\
\text { controlled trial }\end{array}$ & HIV prevention & $\begin{array}{l}\text { To determine whether social networking communities can increase } \\
\text { HIV testing among African American and Latino MSM. }\end{array}$ \\
\hline
\end{tabular}

acceptability of their intervention $(39,40)$. The studies by Young et al. that tested a peer-mentoring intervention were able to confirm its effectiveness compared to a control group.

\section{Types of Participation}

Table 4 maps specific information of the interventions including a brief description of the intervention (if applicable), a more detailed description of the participatory elements, information about the type of digital format and how it was used, and a collection of strengths and weaknesses mentioned in relation to the digital format. The three studies by Young et al. (30-32) are combined in this table as they report the same intervention.

We found five studies that conducted qualitative participatory research. As reported above, four of them used online focus groups as research method $(35,37,38,41)$. One study additionally conducted in-depth interviews (35). In the focus groups and interviews, the researchers sought a nuanced understanding of the participants' views and perspectives on a particular issue affecting their lives. Participants were asked about their experiences, opinions, ideas, thoughts and recommendations. One study used concept mapping as a community-based participatory research method (40). Through this process, community members were enabled to gather their opinions and ideas about how hospitals could help youth avoid violence in the future. After that participants could sort and rate these ideas through an online process. In a face-to-face meeting, these results were developed into an intervention concept.
One intervention enabled peer support using online forums where participants could connect and support each other by starting conversation threads or responding to staff-generated threads (34). Another intervention that also used a peer support approach, trained peers of a community to become peer mentors who provided HIV prevention by communicating with the participants through Facebook groups (30-32).

We found one study that implemented an empowerment project providing opportunity and support for women at risk or living with HIV to identify, create and deliver health-promoting messages in their informal personal networks (39). To facilitate this project, a partnership was established between an academic and community agency.

One study used a crowdsourcing method to allow young people to participate in policy decision-making by both formulating the problems and generating solutions for the AIDS response (36). Similar to the concept mapping process, participants were able to share ideas and vote on what should be included in a strategy paper for the UNAIDS Secretariat, which was created through a public co-authoring process.

\section{Utilization of Digital Formats}

Online focus groups were mostly conducted in an asynchronous manner, meaning that participants did not have to respond immediately. Bridges (35) used the social network platform Facebook for both focus groups and interviews. Focus group questions were posted on a wall using the "event" function, 
TABLE 3 | Methods and results of included studies.

\begin{tabular}{|c|c|c|c|c|c|}
\hline Author, year & Target population and setting & Data collection & Analysis method & Sample participants & Findings \\
\hline Barry et al. (34) & $\begin{array}{l}\text { Age: } 18-30 \\
\text { Sex: males } \\
\text { Setting: Black, gay, bisexual } \\
\text { MSM, recruited in } \\
\text { southeastern US }\end{array}$ & $\begin{array}{l}\text { Posts on the } \\
\text { intervention website }\end{array}$ & $\begin{array}{l}\text { Qualitative content } \\
\text { analysis }\end{array}$ & $\begin{array}{l}\text { Total number: } 48 \\
\text { (RCT: } 474 \text { ) } \\
\text { Average age: } 24.3 \text { years }\end{array}$ & $\begin{array}{l}\text { Findings illustrate the width of roles that } \\
\text { peer-level support played in fostering resilience. } \\
\text { Self-acceptance and sex-positive norms were } \\
\text { identified as new subthemes. }\end{array}$ \\
\hline Bridges (35) & $\begin{array}{l}\text { Age: all ages } \\
\text { Sex: females } \\
\text { Setting: breastfeeding mothers, } \\
\text { members of closed Facebook } \\
\text { groups attached to Australian } \\
\text { Breastfeeding Association }\end{array}$ & $\begin{array}{l}3 \text { online interviews, } 3 \\
\text { online focus groups }\end{array}$ & Thematic analysis & $\begin{array}{l}\text { Total number: } 23 \\
\text { Administrators: } 3 \\
\text { Group members: } 20 \\
\text { Average age: not collected }\end{array}$ & $\begin{array}{l}\text { Online breastfeeding support groups provide } \\
\text { primarily support from a trusted community. } \\
\text { Social networking sites are further described as } \\
\text { immediate, complementary to existing support } \\
\text { services, and a source of information for users. }\end{array}$ \\
\hline Hildebrand et al. (36) & $\begin{array}{l}\text { Age: } 15-29 \\
\text { Sex: all genders } \\
\text { Setting: young people of } 79 \\
\text { countries, connected to the } \\
\text { UNAIDS network }\end{array}$ & $\begin{array}{l}\text { Data from a secondary } \\
\text { analysis of the themes } \\
\text { and texts that emerged } \\
\text { during the UNAIDS } \\
\text { discussions }\end{array}$ & $\begin{array}{l}\text { Focused thematic } \\
\text { analysis }\end{array}$ & $\begin{array}{l}\text { Total number: } 5,102 \\
\text { Online forums: } 3,497 \\
\text { Offline forums: } 1,605 \\
\text { Average age: not collected }\end{array}$ & $\begin{array}{l}\text { Youth identified the need to change the way } \\
\text { sex and relationships are dealt with through } \\
\text { comprehensive sexuality education, } \\
\text { overcoming social and cultural taboos, and } \\
\text { changing how sex is talked about. }\end{array}$ \\
\hline lantaffi et al. (37) & $\begin{array}{l}\text { Age: } 18 \text { or older } \\
\text { Sex: males } \\
\text { Setting: MSM regularly viewing } \\
\text { sexually explicit media, living in } \\
\text { the US }\end{array}$ & 13 online focus groups & Content analysis & $\begin{array}{l}\text { Total number: } 79 \\
\text { Average age: } 18-44 \text { years } \\
\text { (most participants were } \\
\text { white, HIV-negative men) }\end{array}$ & $\begin{array}{l}\text { The acceptable level of sexual explicitness in } \\
\text { HIV prevention campaigns depends on factors } \\
\text { of audience, location, and community } \\
\text { representation. }\end{array}$ \\
\hline Ripat and Colatruglio (38) & $\begin{array}{l}\text { Age: adults } \\
\text { Sex: all genders } \\
\text { Setting: users of wheeled } \\
\text { mobility devices (WMD), } \\
\text { residents of Manitoba, Canada }\end{array}$ & $\begin{array}{l}1 \text { online asynchronous } \\
\text { focus group }\end{array}$ & Content analysis & $\begin{array}{l}\text { Total number: } 8 \\
\text { ( } 7 \text { wheelchair users, } 1 \\
\text { scooter \& walker user) }\end{array}$ & $\begin{array}{l}\text { "Study confirms that elements of the } \\
\text { environment, including the natural environment, } \\
\text { supports, services, policies, and WMDs can } \\
\text { alternatively serve as a barrier or facilitator to } \\
\text { community participation." (p. 102) }\end{array}$ \\
\hline Rothpletz-Puglia et al. (39) & $\begin{array}{l}\text { Age: adults } \\
\text { Sex: females } \\
\text { Setting: women at risk for or } \\
\text { living with HIV, living in } \\
\text { New Jersey }\end{array}$ & $\begin{array}{l}\text { Self-reported activity } \\
\text { logs, participant } \\
\text { questionnaires, and } \\
\text { community-recipient } \\
\text { evaluations }\end{array}$ & $\begin{array}{l}\text { Mixed methods } \\
\text { approach }\end{array}$ & $\begin{array}{l}\text { Total number: } 57 \text { in-person } \\
\text { group: } 38 \text { online group: } 19\end{array}$ & $\begin{array}{l}\text { Women in both groups successfully provided } \\
\text { health promotion to } 5,861 \text { people in their social } \\
\text { networks. This demonstrates the feasibility of } \\
\text { building social networks for disseminating } \\
\text { health information and reducing health } \\
\text { disparities in communities. }\end{array}$ \\
\hline Snider et al. (40) & $\begin{array}{l}\text { Age: youth and adults } \\
\text { Sex: all genders } \\
\text { Setting: youths, parents, and } \\
\text { community youth workers, } \\
\text { recruited in Toronto }\end{array}$ & $\begin{array}{l}\text { Data was collected } \\
\text { through 'The Concept } \\
\text { System' software }\end{array}$ & Cluster analysis & $\begin{array}{l}\text { Total number: } 278 \\
\text { Brainstorming: } 48 \\
\text { Sorting: } 103 \\
\text { Rating: } 102 \\
\text { Interpretation: } 25 \\
\text { Average age (if } \\
\text { youth): } 12-24\end{array}$ & $\begin{array}{l}\text { It is feasible to use information generated by } \\
\text { youth to develop successful and meaningful } \\
\text { interventions to prevent youth violence. }\end{array}$ \\
\hline
\end{tabular}


TABLE 3 | Continued

Author, year Target population and setting

Data collection

Age: $14-18$

Sex: males

Setting: gay, bisexual, and queer

males, recruited nationally (USA)

Young et al. (30)

Age: 18 or older

Sex: males

Setting: Participants and peer

leaders are MSM with a

Facebook account, living in Lima

(Peru). Participants should be

HIV negative or

Young et al. (31)

serostatus unknown.

Age: 18 or older

Sex: males

Setting: Participants and peer

leaders are MSM with a

Facebook account, living in Los

Angeles. Peer leaders should be

African American or Latino.

Young et al. (32)

Age: 18 or older

Sex: males

Setting: Participants and peer

leaders are MSM with a

Facebook account, living in Los

Angeles. Peer leaders should be

African American or Latino.

\section{4 questions}

subsequent to online

focus groups

Baseline survey before

the intervention

\section{Multivariate \\ adjusted logistic \\ regression}

Thematic analysis
Multivariate
adjusted logistic
regression

Baseline and follow-up survey, participants' FB

friend lists

Network

visualizations,

regression

analyses

Baseline and follow-up

survey

Chi-square tests,

$t$-tests, rates of

home-based HIV

testing
Sample participants

Total number: 75

Group with no sexual

experience: 36

Group with sexual

experience: 39

Total number: 498

Intervention group: 252

Control group: 246

Peer leaders: 34

Average age: 28.9 years

Total number: 105

Peer leaders: 16

Average age: 31.5 years

(90\% were Latino or

African American)

Total number: 105

Peer leaders: 16

Average age: 31.5 years

(90\% were Latino or

African American)

\section{Finding}

The majority reported that their participation

positively changed their views and behaviora

intentions about their sexuality. Sexually

inexperienced youth most commonly reported

positive effects of feeling less isolated.

Participants in the HIV intervention groups were

more likely to request an HIV test than were

those in the control groups. Peer-mentored

social media communities seemed to be an

effective method to increase HIV testing among

high-risk populations in Peru

Among the intervention group, a positiv trending relationship between increased network ties and likelihood of HIV testing, follow-up for test results, and participation in online community discussions was found.

"Social networking communities are acceptable and effective tools to increase home-based HIV testing among at-risk populations." (p. 2) 
TABLE 4 | Characteristics of interventions.

\section{Author, year Description of intervention}

Barry et al. HealthMpowerment is an onlin

$\begin{array}{ll}\text { Barry et al. } & \text { HealthMpowerment is an online } \\ \text { (34) } & \text { intervention that aimed to reduce }\end{array}$ condomless anal intercourse and foster community among young Black GBMSM. In online forums the intervention group could react to pre-populated or staff-generated conversations (control group got an information-only website).

Hildebrand CrowdOutAIDS is a participatory et al. (36) online policy project using a

Crowdsourcing 1) A community of interested young people were connected 2) You

1) Social media

process to enable

crowdsourcing process. It consists
4 steps to enable young people to both formulate the problems as well as generate solutions in the AIDS

response, resulting in a strategy document for the UNAIDS Secretariat.
Participatory

In the interviews and focus groups, research via online participants were asked about their in-depth interviews experiences administering or and online focus participating in closed Facebook groups ideas, and information 3) Participants $\quad$ 2) Social were enabled to find solutions networkin via voting 4) Final strategy document platforms: was co-authored in public online Facebook, sessions, and a drafting committee of RenRen and young people worked with the Vkontakte
Social media platform Facebook via the "Messenger"

used for qualitative function. Questions were interviews and typed in and answered focus groups synchronously by the participants.

The focus groups were conducted via the "Event" function. All questions were created as wall posts and answered asynchronously by participants via the "comment" function.

1) Initial buzz via social media and implementation via the online UNAIDS Secretariat to implement $\quad$ 3) Customized the strategy conducted via Facebook, RenRen, and Vkontakte 3) Customized osqa.net application for voting 4) Customized GoogleDocs application (no further description provided)

- The digital crowdsourcing - Digital divide processes facilitates the integration of grassroots (a), engagement, and participation. "ordinary" young people Despite the digital divide, be useols can effectively be used to mobilize
offline action." (p. 67) 


\section{TABLE 4 | Continued}

\begin{tabular}{|c|c|c|c|c|c|c|c|}
\hline Author, year & Description of intervention & $\begin{array}{l}\text { Type of } \\
\text { community } \\
\text { participation }\end{array}$ & $\begin{array}{l}\text { Description of participatory } \\
\text { activities }\end{array}$ & $\begin{array}{l}\text { Type of digital } \\
\text { element }\end{array}$ & $\begin{array}{l}\text { Description of digital } \\
\text { elements }\end{array}$ & $\begin{array}{l}\text { Benefits related to the } \\
\text { digital format }\end{array}$ & $\begin{array}{l}\text { Limitations } \\
\text { related to the } \\
\text { digital format }\end{array}$ \\
\hline $\begin{array}{l}\text { lantaffi et al. } \\
\text { (37) }\end{array}$ & I & $\begin{array}{l}\text { Participatory } \\
\text { research via online } \\
\text { focus groups }\end{array}$ & $\begin{array}{l}\text { Participants were asked to give their } \\
\text { opinions on HIV-prevention poster } \\
\text { advertisements and one video } \\
\text { advertisement }\end{array}$ & $\begin{array}{l}\text { Adobe Connect } \\
\text { used for online } \\
\text { synchronous focus } \\
\text { groups, bulletin } \\
\text { board for } \\
\text { asynchronous } \\
\text { follow-up } \\
\text { questions }\end{array}$ & $\begin{array}{l}\text { The synchronous focus } \\
\text { groups were conducted via } \\
\text { the "chat" function, without } \\
\text { the use of audio or video. } \\
\text { After conclusion, } \\
\text { participants were invited to } \\
\text { respond asynchronously to } \\
\text { follow-up questions and } \\
\text { comments posted on a } \\
\text { message board. }\end{array}$ & $\begin{array}{l}\text { Higher confidentiality, by not } \\
\text { using audio or video } \\
\text { functions. }\end{array}$ & $\begin{array}{l}\text { Data is limited to } \\
\text { written text and } \\
\text { does not give } \\
\text { access to audio or } \\
\text { visual participants' } \\
\text { reactions. }\end{array}$ \\
\hline $\begin{array}{l}\text { Ripat and } \\
\text { Colatruglio } \\
\text { (38) }\end{array}$ & I & $\begin{array}{l}\text { Participatory } \\
\text { research via online } \\
\text { focus group }\end{array}$ & $\begin{array}{l}\text { "The researchers were seeking a } \\
\text { nuanced understanding of WMD } \\
\text { users' experiences regarding } \\
\text { community participation and winter } \\
\text { barriers, the strategies they employ to } \\
\text { overcome those barriers, and the } \\
\text { recommendations they had for } \\
\text { improving winter community } \\
\text { participation." (p. 97) }\end{array}$ & $\begin{array}{l}\text { WordPress.com } \\
\text { for hosting } \\
\text { asynchronous } \\
\text { online focus group }\end{array}$ & $\begin{array}{l}\text { Participants had } 1 \text { week to } \\
\text { respond asynchronously to } \\
\text { daily questions posed by a } \\
\text { moderator. }\end{array}$ & $\begin{array}{l}\text { "Time for more in-depth and } \\
\text { reflective responses from } \\
\text { participants, greater } \\
\text { participant anonymity, } \\
\text { increased convenience in } \\
\text { terms of participating from } \\
\text { any location at any time, } \\
\text { and automatic capture of } \\
\text { discussion data" (p. } 97)\end{array}$ & / \\
\hline $\begin{array}{l}\text { Rothpletz- } \\
\text { Puglia et al. } \\
\text { (39) }\end{array}$ & $\begin{array}{l}\text { Shout-out Health is a } \\
\text { community-driven health promotion } \\
\text { approach aiming to empower } \\
\text { high-risk community members to } \\
\text { develop and provide health promotion } \\
\text { messaging delivered in their informal } \\
\text { social networks. }\end{array}$ & $\begin{array}{l}\text { Empowerment } \\
\text { intervention for } \\
\text { providing health } \\
\text { promotion in } \\
\text { informal social } \\
\text { networks }\end{array}$ & $\begin{array}{l}\text { Within in-person or online groups } \\
\text { participants identified health problems } \\
\text { and developed ways to promote } \\
\text { health information in their informal } \\
\text { social networks over a 5-6 week } \\
\text { period. Therefor a 5-step intervention } \\
\text { process was conducted. }\end{array}$ & $\begin{array}{l}\text { Asynchronous } \\
\text { online group (no } \\
\text { information about } \\
\text { the program) }\end{array}$ & $\begin{array}{l}\text { Over a 3-month period, } \\
\text { women in the online group } \\
\text { worked asynchronously } \\
\text { except for } 2 \\
\text { conference calls. For the } \\
\text { participants' convenience, } \\
\text { they could choose the } \\
\text { meeting format but could } \\
\text { not move back and forth } \\
\text { between the } 2 \text { approaches. } \\
\text { (no further } \\
\text { description provided) }\end{array}$ & $\begin{array}{l}\text { - Convenience for } \\
\text { participants to choose } \\
\text { between online and } \\
\text { in-person group } \\
\text { - No significant differences } \\
\text { in the productivity by group } \\
\text { meeting format (p. 3) }\end{array}$ & I \\
\hline
\end{tabular}


TABLE 4 | Continued

Author, year Description of intervention

Type of

community

Description of participatory

activities

element

participation

Snider et al. /

(40)

Community-based Opinions and ideas from community participatory members about how hospitals could research using help youth avoiding violence in the concept mapping future were collected, sorted, and rated online. In a face-to-face meeting, participants discussed the assessment results and drafted an intervention concept.

"The Concept

\section{1) Brainstorming:}

System" software participants were asked to

for conducting the enter statements in

online concept response to a prompt

(8 weeks) 2) Sorting: onlin

participant sorted the

brainstormed statements

into piles (6 weeks) 3)

Rating: participants rated

each statement in terms of

importance (6 weeks)

Participatory Participants took part in two rounds research via online of asynchronous focus groups in focus groups which they discussed their ideas,

Bulletin board

used for

asynchronous

"Each day, questions were posted on the bulletin board in the morning and then thoughts, and concerns about an HIV focus groups and prevention program. Afterward, they were asked 4 questions how their participation in the focus groups influenced or changed their views or behaviors.

Young et al. The HOPE Social Media Intervention Peer-mentoring tested whether MSM in Facebook groups with peer-mentored HIV prevention and behavior change information would be more likely to test for HIV than those in groups without a peer-leader. community were trained as

peer-leaders. They were advised to communicate with their assigned participants on Facebook in addition

to general "friendly" conversation about HIV prevention and testing and peer support well-respected among the MSM

moderator probes, and posts. Participants had no

obligations to respond or to

\section{the following}

questions

the afternoon.

Participants were instructed

to visit the board at least

twice a day to respond to

questions, reply to

interact in discussions with

other group members."

(p. 3)

Social media Private Facebook groups - Low costs HIV solution

platform Facebook consisted of 30 participants

used for

and 4-6 peer leaders who

conducting online communicated by sending intervention Broader reach than traditional public health interventions

- Reduce travel and time

groups scalable intervention stay in the Facebook group. costs

Easy implementation

- Growing international

popularity of social media

- Easier data collection than in field settings

Limitations

related to the

digital format

- Due to anonymity, determination of how many participants took part in all four steps not possible - "A limitation of the software used in this study is a restriction on the number of demographic questions that can be asked." (p. 883) nvironment, in which freely about their sexuality
- Duplicate respondents found during recruiting (non-unique usernames) 
interview questions were typed in via the "messenger" function. Iantaffi et al. (37) used Adobe Connect for conducting synchronous focus groups via the "chat" function, without the audio or video function, and an asynchronous bulletin board for follow-up questions. The online focus group of Ripat and Colatruglio (38) was also conducted in an asynchronous manner by commenting on questions from a moderator hosted on WordPress.com. Ybarra et al. (41) used a bulletin board to conduct the focus groups and the subsequent behavior change questions. Participants were able to respond to questions, reply to moderator probes and interact in discussions with other group members.

Barry (34) used a website that was later optimized by a mobile phone application, which offered two online forums. In both forums, participants had the opportunity to read and contribute to existing conversation threads or start new threads and to post and respond to topics with videos, poems, reflections, audio, and pictures.

The HOPE Social Media Intervention was conducted via the social networking platform Facebook by creating closed groups in which the peer mentors could communicate with the participants by sending messages, chats, and wall posts (30-32).

Snider et al. (40) used a special program called The Concept System for the concept mapping process, in which participants could brainstorm ideas online, sort them, and rate them over a period of several weeks.

The CrowdOutAIDS program used various online applications for its four-step crowdsourcing process. Participants were recruited via social media and directed to the CrowdOutAIDS.org website. Online forums were then conducted through the social networks Facebook, RenRen and Vkontakte, and additional community forums were organized through online participant volunteers. Statements abstracted from the forums were voted for via a customized osqa.net application. In subsequent public online sessions, the final strategy document was created in a co-authoring process via a customized GoogleDocs application. A more detailed description of the applications was not provided.

The Empowerment project by Rothpletz-Puglia et al. (39) offered a choice between online and in-person groups. The online group worked asynchronously except for two conference calls. More information about the digital format and its usage was not provided.

\section{Benefits and Limitations Associated With Digital Approach}

One of the strengths of online forums is that they offered anonymity, which facilitated discussion of more candid questions (40). It was also noted by Barry et al. (34) that communication via online platforms came close to their real-life interactions and was therefore familiar. In addition, the flexibility for participants to decide how and what to contribute was mentioned as a strength. As a limitation, the difficulty of interpreting the tone and intention of online data was noted.

Similar points were mentioned in the study from Iantaffi et al. (37). The anonymity of online focus groups offered higher confidentiality by not using audio or video functions, but the lack of access to audio or visual participants' reactions made the interpretation of the data more difficult.

Snider et al. (40) concluded that anonymity is a strength of the online concept mapping process, which was particularly valuable with regard to the topic of experienced violence. Also, the flexibility of allowing participants to decide for themselves whether they wanted to participate in any or all steps was cited as a strength. The disadvantage of this procedure, however, was that it was not possible to evaluate how many participants took part in all steps of the process.

Ybarra et al. (41) also mentioned that the online format created a safe and anonymous environment that allowed participants to talk more freely about their sexuality. Moreover, it is added that online focus groups can represent a scalable low-cost intervention.

The social media intervention The HOPE was also identified as a low-cost solution for HIV prevention that enabled a broader reach than traditional public health interventions, was easy to implement, reduced travel and time costs and facilitated data collection (30-32). A disadvantage of social media interventions was cited as finding duplicate respondents during recruitment through non-unique usernames.

Hildebrand et al. (36) highlighted the broader reach of digital methods as a strength, enabling the integration of grassroots perspectives from across the globe and the involvement of young people who would not have normally been involved through traditional participatory processes. As a limitation of digital formats, Hildebrand mentioned the digital divide and the associated selection bias, as it was assumed that online participants have a higher socioeconomic background.

Conducting the asynchronous focus groups and interviews via Facebook was beneficial for easy accessibility and flexibility for participants to decide for themselves the time and place they want to respond (35). Especially for young mothers this format was considered suitable.

Ripat and Colatruglio (38) mentioned the increased convenience in terms of participating from any location at any time given by online focus groups, in addition to anonymity, the automatic data collection, and the fact that participants have time to give more reflective responses.

Rothpletz-Puglia et al. (39) compared the productivity between online groups and in-person groups and found no significant differences. They described the possibility to choose between both formats as a convenience for participants.

\section{DISCUSSION}

With this scoping review we mapped the existing literature on digital formats that enable participation in the field of health promotion and prevention in community settings. Furthermore, we gained a more comprehensive understanding of core concepts in this research area in terms of the enabled types of participation, the ways of utilizing the digital formats and the benefits and limitations linked to it. We identified nine unique out of 11 included studies relevant to the research question. Although these 
are a relatively small number of studies, they seem to reflect to some extent the diversity of methods and topics as well as certain trends in the literature.

\section{Characteristics of Included Studies}

The majority of included studies dealt with vulnerable populations, mostly targeting communities at risk for or living with HIV. The huge amount of studies focusing on community-based HIV prevention programs and activities was also noticeable in the title and abstract screening. This may indicate that digital interventions are often used to reach stigmatized or vulnerable groups who commonly face challenges in seeking support. The easier accessibility and anonymity are particularly beneficial for reaching those populations (42).

Only youths and younger adults between 12 and 44 years were targeted or included in the interventions of our selected studies. This may reflect the fact that this age group can be reached better and more easily using digital media than older adults. As interpersonal interactions of younger adults increasingly take place online, digital interventions more closely resemble their real-life interactions than they do for older people, who generally have less exposure to digital media and lower levels of e-health literacy $(34,43)$.

\section{Types of Participation}

We found three studies that used community participation methods, like crowdsourcing and concept mapping, to enable large groups of people to actively define relevant issues for their community themselves and help shape solutions. We also found participatory research studies that mostly used a focus group approach. Through this method, participants were able to express their views and perspectives on a specific issue affecting their lives. The deeper insights into participants' experiences, opinions, thoughts, and recommendations not only benefited the researchers in generating more detailed data. Through participation in focus groups, community members reported benefits including new insights and a broader perspective on issues shared within the group, in addition to a sense of inclusion and community building (44). This was most evident in the study by Ybarra et al. (41), which found that online focus groups discussions should be further explored as low-cost prevention programs.

\section{Utilization of Digital Formats}

The digital technologies used varied widely, from social media platforms to customized web providers and programs. Digital technologies were used in most cases to establish direct communication between researchers and participants or to establish communication between participants. In the crowdsourcing, and concept mapping interventions, digital formats were used for mass community engagement that enabled democratic processes such as voting, brainstorming, sorting and rating. These findings demonstrate that digital technologies can, on the one hand, facilitate communication between community members and thus foster social networks. On the other hand, they can be used to create open environments to involve large groups of individuals for community participation processes (45).
Crowdsourcing, in particular, is a method of mass collaboration that increases in the field of public health (27).

\section{Benefits and Limitations Associated With Digital Approach}

Three studies found that the interaction with like-minded people in online spaces increased feelings of support and self-acceptance among participants and reduced feelings of isolation $(34,35,41)$. It was stated that the anonymity facilitated by the digital formats was beneficial to these interactions, as well as the easy and immediate access to support and flexibility to decide how much and when to participate. This is congruent with the reasons why digital peer support formats are increasingly offered in the field of mental health identified by a systematic review (46). Most of our identified qualitative participatory research studies used online asynchronous focus groups. For this method it is essential to create a "safe space" where participants have a feeling of confidentiality to express their opinions and experiences freely. The frequent choice for asynchronous formats could be an indication that this necessary environment can be created particularly well by this approach, by allowing a higher degree of anonymity and flexibility for participants to determine when and where to respond.

None of the included studies mentioned ethical aspects and data protection issues as a limitation or barrier of digital formats. This may be due to the fact that the majority of studies were from Anglo-American countries. This should be taken into account when transferring the study concepts to countries with high data protection requirements, such as Germany. Only five studies reported limitations related to the digital format, including difficult interpretation of written data. Previous research has already indicated that sufficient written literacy must be a criterion when conducting interventions limited to written discussions (47). This carries the risk of excluding certain groups of people, which is why suitability for the target population needs to be considered. In the title and abstract screening, we also found many studies on photovoice that were often not included because the subsequent focus group discussions were mostly conducted in a non-digital format. Since photovoice is less about examining participants' views on something and more about creating an impact, face-to-face formats may be better suited for this purpose (48).

Existing studies on digital interventions in various community settings mention several benefits compared to traditional formats. A review by Gilbey et al. (42) outlined in regard of the LGBTQ (lesbian, gay, bisexual, transgender, queer) community the anonymity aspect of digital interventions which facilitates access to support by minimizing stigma. Wadham et al. (49) found that specific communities like adolescents and young adults can be easier reached with new digital media interventions, because they use digital ways for information sharing on a regular basis. A review by Fortuna et al. (46) mentioned that digital peer support is increasingly delivered through social media networks, smartphone apps, and technologies that enable synchronous and asynchronous communication. This allows for a wider reach of peer support services. Digital interventions 
also become increasingly popular due to easy implementation, cost-effectiveness, and remote accessibility (50). On the other side, higher drop-out rates and a lack of evidence on the effectiveness of digital interventions have been reported $(42,51)$. Additionally, according to Hall et al. (52), aspects of "poor technology skills, interfaces that are not user-friendly, concerns around data security, and a lack of support from healthcare professionals" should be considered when implementing digital interventions.

The COVID-19 pandemic resulted in the implementation of certain non-pharmaceutical measures, such as cancelling public events, restricting social gatherings to a minimum and closing schools and workplaces (53). Social distancing demonstrated the need and potential for using digital solutions with a consistent digital approach to engage people in health promotion and prevention activities.

However, there are some open questions with regard to the implementation of digital formats in community-based health promotion interventions which should be focused on in future research activities. It should be considered carefully whether digital formats could replace traditional formats for health promotion and prevention activities especially in vulnerable populations. From our perspective, one of the most urgent unanswered questions is whether the implementation of digital health promotion interventions leads to a further increase of a selection bias or whether such interventions counteract this bias and are used and accepted by vulnerable groups and settings in which traditional formats fail.

\section{Strengths and Limitations}

This review contains some methodological limitations. First, we may have missed some relevant studies related to the research questions for a few reasons. Our search was restricted to three databases without including grey literature. We searched for publications in English only and therefore might have missed studies published in other languages from geographic areas where digital public health technologies are known to be widely used (e.g., Korea, Japan). There were also a high number of studies that had to be excluded because the full texts were not available. In addition, we conducted the database search in November 2020, which may have been too early to find relevant studies related to the COVID-19 pandemic. Second, we did not perform a quality assessment of the included studies and did not focus on ethical and data protection aspects of using digital formats. However, this was not considered relevant to the objective of this study, which was to collect existing literature on this topic and examine it for key concepts. Considering the relatively low number of included studies compared to the number of papers found by the literature search, this might be explained by the clearly defined and specific inclusion criteria, as we were looking for interventions with a high level of participation for communities and a high proportion of digital implementation in the intervention. This focus was also reflected in the search strategy, where we searched specifically for community, participation and their synonymous terms. These criteria were needed for narrowing the amount of publications found at the initial search. However, this may have led to the omission of publications that might have been of interest for our work. Despite these limitations, we do consider this clear focus to be a strength and a quality criterion of this paper.

Other strengths of this review were the sound methodology based on recommended frameworks of Arksey and O'Malley and the PRISMA checklist for preferred reporting items.

\section{CONCLUSION}

This scoping review only found a few studies following a consequent digital format to enable a high level of community participation in health promotion and prevention, indicating an existing gap in research on this topic. Digital formats were found to be suitable for purposes where anonymity is helpful. In the included studies, this was apparent in qualitative participatory research studies, particularly in online focus groups that required participants to talk about sensitive subjects. Furthermore, the aspects of anonymity and easy accessibility appeared to be beneficial in supporting vulnerable and stigmatized communities, such as through peer exchanges and peer support programs. Further research should be conducted on the purposes for which digital formats can be more effective than traditional formats in enabling participation, in order to make more targeted use of the potential of digital technologies and social media. Disadvantages of digital formats, such as possible selection bias due to the digital divide and difficulties in interpreting written-only data, have to be weighed against the benefits. The consequences of social distancing due to the COVID19 pandemic and the unpredictability of similar exceptional circumstances in the future stress the need to further develop and implement digital formats in health promotion and prevention activities in community settings.

\section{AUTHOR CONTRIBUTIONS}

CS conducted the database search. During the screening process, CS screened all records in the title/abstract and in the full-text screening stage. MC, SV, and CJ-S divided half of the records among each other during the title/abstract screening. In the fulltext screening phase, $\mathrm{MC}$ and $\mathrm{SV}$ screened half of the records each. CS, SV, and MC were involved in the data extraction process. CS drafted the first version of this manuscript and developed it further based on feedback from SV and MC. CS, SV, CJ-S, and MC all read, reviewed, and approved of the final version of the manuscript. All authors contributed to the conception of the study and the development of the search strategy. 


\section{REFERENCES}

1. World Health Organization. Ottawa Charter for Health Promotion: First International Conference on Health Promotion Ottawa. (1986). Available online at: https://www.euro.who.int/_data/assets/pdf_file/0004/129532/ Ottawa_Charter.pdf (accessed February 6, 2021).

2. World Health Organization. Declaration of Alma-Ata International Conference on Primary Health Care, Alma-Ata, USSR, 6-12 September 1978. Development. (2004) 47:159-61. doi: 10.1057/palgrave.development.1100047

3. George AS, Mehra V, Scott K, Sriram V. Community participation in health systems research: a systematic review assessing the state of research, the nature of interventions involved and the features of engagement with communities. PLoS ONE. (2015) 10:e0141091. doi: 10.1371/journal.pone.0141091

4. O'Mara-Eves A, Brunton G, Oliver S, Kavanagh J, Jamal F, Thomas J. The effectiveness of community engagement in public health interventions for disadvantaged groups: a meta-analysis. BMC Public Health. (2015) 15:129. doi: $10.1186 /$ s12889-015-1352-y

5. Abbott S. Social capital and health: the role of participation. Soc Theory Health. (2010) 8:51-65. doi: 10.1057/sth.2009.19

6. Navarro AM, Voetsch KP, Liburd LC, Giles HW, Collins JL. Charting the future of community health promotion: recommendations from the National Expert Panel on Community Health Promotion. Prev Chronic Dis. (2007) 4:A68.

7. Jeffres LW. Community. In: Michalos AC, editor. Encyclopedia of Quality of Life and Well-Being Research. Dordrecht: Springer. (2014). p. 1034-6.

8. Springer MV, Skolarus LE. Community-based participatory research. Stroke. (2019) 50:e48-50. doi: 10.1161/STROKEAHA.118.024241

9. Arnstein SR. A ladder of citizen participation. J Am Inst Plann. (1969) 35:216-24. doi: 10.1080/01944366908977225

10. Wright, MT, Block M, von Unger H, editor. Partizipative Qualitätsentwicklung in der Gesundheitsförderung und Prävention. 1. Aufl. s.l: Verlag Hans Huber (2010). Available online at: http://elibrary.hogrefe.de/9783456948676/ A (accessed October 22, 2021).

11. Duarte AMB, Brendel N, Degbelo A, Kray C. Participatory design and participatory research. ACM Trans Comput Hum Interact. (2018) 25:139. doi: $10.1145 / 3145472$

12. Bethmann A, Hilgenböcker E, Wright M. Partizipative Qualitätsentwicklung in der Prävention und Gesundheitsförderung. In: Tiemann M, Mohokum M, editors. Prävention und Gesundheitsförderung. Berlin, Heidelberg: Springer Berlin Heidelberg (2020). p. 1-13.

13. Zeeb H, Pigeot I, Schüz B. Digital Public Health - Rasanter technischer Fortschritt, aber viele offene Public-Health-Fragen. Bundesgesundheitsblatt Gesundheitsforschung Gesundheitsschutz. (2020) 63:135-6. doi: 10.1007/s00103-020-03092-0

14. Clar C, Dyakova M, Curtis K, Dawson C, Donnelly P, Knifton L, et al. Just telling and selling: current limitations in the use of digital media in public health: a scoping review. Public Health. (2014) 128:106675. doi: 10.1016/j.puhe.2014.09.009

15. Munn Z, Peters MDJ, Stern C, Tufanaru C, McArthur A, Aromataris E. Systematic review or scoping review? Guidance for authors when choosing between a systematic or scoping review approach. BMC Med Res Methodol. (2018) 18:143. doi: 10.1186/s12874-018-0611-x

16. Peters MDJ, Godfrey CM, Khalil H, McInerney P, Parker D, Soares CB. Guidance for conducting systematic scoping reviews. Int J Evid Based Healthc. (2015) 13:141-6. doi: 10.1097/XEB.0000000000000050

17. Arksey H, O’Malley L. Scoping studies: towards a methodological framework. Int J Soc Res Methodol. (2005) 8:19-32. doi: 10.1080/1364557032000119616

18. Levac D, Colquhoun H, O’Brien KK. Scoping studies: advancing the methodology. Implement Sci. (2010) 5:69. doi: 10.1186/1748-5908-5-69

19. Daudt HML, van Mossel C, Scott SJ. Enhancing the scoping study methodology: a large, inter-professional team's experience with Arksey and O'Malley's framework. BMC Med Res Methodol. (2013) 13:48. doi: 10.1186/1471-2288-13-48

20. Peters MDJ, Godfrey CM, McInerney P, Soares CB, Khalil H, Parker D. The Joanna Briggs Institute Reviewers' Manual 2015: Methodology for JBI Scoping Reviews. Joanna Briggs Institute, The University of Adelaide, Adelaide, SA, Australia (2015).
21. Tricco AC, Lillie E, Zarin W, O'Brien KK, Colquhoun H, Levac D, et al. PRISMA Extension for Scoping Reviews (PRISMA-ScR): checklist and explanation. Ann Intern Med. (2018) 169:467-73. doi: 10.7326/M18-0850

22. Campbell IH, Rudan I. Effective approaches to public engagement with global health topics. J Glob Health. (2020) 10:1040901. doi: 10.7189/jogh.10.010901

23. Dogba MJ, Dossa AR, Breton E, Gandonou-Migan R. Using information and communication technologies to involve patients and the public in health education in rural and remote areas: a scoping review. BMC Health Serv Res. (2019) 9:128. doi: 10.1186/s12913-019-3906-7

24. Kruse C, Betancourt J, Ortiz S, Valdes Luna SM, Bamrah IK, Segovia $\mathrm{N}$. Barriers to the use of mobile health in improving health outcomes in developing countries: systematic review. J Med Internet Res. (2019) 21:e13263. doi: $10.2196 / 13263$

25. Ronen K, Grant E, Copley C, Batista T, Guthrie BL. Peer group focused eHealth strategies to promote HIV prevention, testing, and care engagement. Curr HIV/AIDS Rep. (2020) 17:557-76. doi: 10.1007/s11904-020-00527-w

26. Sharma AE, Frederiksen BN, Malcolm NM, Rollison JM, Carter MW. Community education and engagement in family planning: updated systematic review. Am J Prev Med. (2018) 55:747-58. doi: 10.1016/j.amepre.2018.06.022

27. Wu D, Ong JJ, Tang W, Ritchwood TD, Walker JS, Iwelunmor J, et al. Crowdsourcing methods to enhance HIV and sexual health services: a scoping review and qualitative synthesis. J Acquir Immune Defic Synd. (2019) 82(Suppl. 3):S271-8. doi: 10.1097/QAI.0000000000002193

28. Catalani C, Minkler M. Photovoice: a review of the literature in health and public health. Health Educ Behav. (2010) 37:42451. doi: $10.1177 / 1090198109342084$

29. Agdal R, Midtgård IH, Meidell V. Can asset-based community development with children and youth enhance the level of participation in health promotion projects? A qualitative meta-synthesis. Int J Environ Res Public Health. (2019) 16:3778. doi: 10.3390/ijerph16193778

30. Young SD, Cumberland WG, Nianogo R, Menacho LA, Galea JT, Coates T. The HOPE social media intervention for global HIV prevention in Peru: a cluster randomised controlled trial. The Lancet HIV. (2015) 2:e2732. doi: 10.1016/S2352-3018(14)00006-X

31. Young SD, Holloway I, Jaganath D, Rice E, Westmoreland D, Coates T. Project HOPE: online social network changes in an HIV prevention randomized controlled trial for African American and Latino men who have sex with men. Am J Public Health. (2014) 104:1707-12. doi: 10.2105/AJPH.2014.301992

32. Young SD, Cumberland WG, Lee SJ, Jaganath D, Szekeres G, Coates T. Social networking technologies as an emerging tool for HIV prevention: a cluster randomized trial. Ann Intern Med. (2013) 159:318-24. doi: 10.7326/0003-4819-159-5-201309030-00005

33. Page MJ, McKenzie JE, Bossuyt PM, Boutron I, Hoffmann TC, Mulrow CD, et al. The PRISMA 2020 statement: an updated guideline for reporting systematic reviews. BMJ. (2021) 372:n71. doi: 10.1136/bmj.n71

34. Barry MC, Threats M, Blackburn NA, LeGrand S, Dong W, Pulley DV, et al. "Stay strong! keep ya head up! move on! it gets better!!!!": resilience processes in the healthMpowerment online intervention of young black gay, bisexual and other men who have sex with men. AIDS Care. (2018) 30(suppl. 5):S27-38. doi: 10.1080/09540121.2018.1510106

35. Bridges $\mathrm{N}$. The faces of breastfeeding support: experiences of mothers seeking breastfeeding support online. Breastfeed Rev. (2016) 24:11-20.

36. Hildebrand M, Ahumada C, Watson S. CrowdOutAIDS: crowdsourcing youth perspectives for action. Reprod Health Matters. (2013) 21:5768. doi: 10.1016/S0968-8080(13)41687-7

37. Iantaffi A, Wilkerson JM, Grey JA, Rosser BRS. Acceptability of sexually explicit images in HIV prevention messages targeting men who have sex with men. J Homosex. (2015) 62:1345-58. doi: 10.1080/00918369.2015.1060066

38. Ripat J, Colatruglio A. Exploring winter community participation among wheelchair users: an online focus group. Occup Ther Health Care. (2016) 30:95-106. doi: 10.3109/07380577.2015.1057669

39. Rothpletz-Puglia P, Jones VM, Storm DS, Parrott JS, O’Brien KA. Building social networks for health promotion: shout-out health, New Jersey, 2011. Prev Chronic Dis. (2013) 10:E147. doi: 10.5888/pcd10.130018

40. Snider CE, Kirst M, Abubakar S, Ahmad F, Nathens AB. Communitybased participatory research: development of an emergency department-based 
youth violence intervention using concept mapping. Acad Emerg Med. (2010) 17:877-85. doi: 10.1111/j.1553-2712.2010.00810.x

41. Ybarra ML, DuBois LZ, Parsons JT, Prescott TL, Mustanski B. Online focus groups as an HIV prevention program for gay, bisexual, and queer adolescent males. AIDS Educ Prev. (2014) 26:554-64. doi: 10.1521/aeap.2014.26.6.554

42. Gilbey D, Morgan H, Lin A, Perry Y. Effectiveness, acceptability, and feasibility of digital health interventions for LGBTIQ+ young people: systematic review. J Med Internet Res. (2020) 22:e20158. doi: 10.2196/20158

43. Schaeffer D, Vogt D, Berens EM, Hurrelmann K. Gesundheitskompetenz der Bevölkerung in Deutschland. Bielefeld: Ergebnisbericht (2016).

44. Nared J, Bole D. Participatory Research and Planning in Practice. Cham: Springer International Publishing (2020).

45. Tucker JD, Day S, Tang W, Bayus B. Crowdsourcing in medical research: concepts and applications. PeerJ. (2019) 7:e6762. doi: 10.7717/peerj.6762

46. Fortuna KL, Naslund JA, LaCroix JM, Bianco CL, Brooks JM, Zisman-Ilani Y, et al. Digital peer support mental health interventions for people with a lived experience of a serious mental illness: systematic review. JMIR Ment Health. (2020) 7:e16460. doi: 10.2196/16460

47. Hansen K. Using An Asynchronous Discussion Board For Online Focus Groups: A Protocol And Lessons Learned. In: College Teaching \& Learning Conference. Orlando, FL (2006).

48. Hartung S, Wihofszky P, Wright MT. Partizipative Forschung. Wiesbaden: Springer Fachmedien Wiesbaden (2020).

49. Wadham E, Green C, Debattista J, Somerset S, Sav A. New digital media interventions for sexual health promotion among young people: a systematic review. Sex Health. (2019) 16:101-23. doi: 10.1071/SH18127

50. Howarth A, Quesada J, Silva J, Judycki S, Mills PR. The impact of digital health interventions on health-related outcomes in the workplace: a systematic review. Digit Health. (2018) 4:2055207618770861. doi: 10.1177/2055207618770861

51. Marcolino MS, Oliveira JAQ, D’Agostino M, Ribeiro AL, Alkmim MBM, Novillo-Ortiz D. The impact of mHealth interventions: systematic review of systematic reviews. JMIR Mhealth Uhealth. (2018) 6:e23. doi: $10.2196 /$ mhealth. 8873

52. Hall CL, Sanderson C, Brown BJ, Andrén P, Bennett S, Chamberlain LR, et al. Opportunities and challenges of delivering digital clinical trials: lessons learned from a randomised controlled trial of an online behavioural intervention for children and young people. Trials. (2020) 21:1011. doi: 10.1186/s13063-020-0 $4902-1$

53. Askitas N, Tatsiramos K, Verheyden B. Estimating worldwide effects of non-pharmaceutical interventions on COVID-19 incidence and population mobility patterns using a multipleevent study. Sci Rep. (2021) 11:1972. doi: 10.1038/s41598-021-8 $1442-\mathrm{x}$

Conflict of Interest: The authors declare that the research was conducted in the absence of any commercial or financial relationships that could be construed as a potential conflict of interest.

Publisher's Note: All claims expressed in this article are solely those of the authors and do not necessarily represent those of their affiliated organizations, or those of the publisher, the editors and the reviewers. Any product that may be evaluated in this article, or claim that may be made by its manufacturer, is not guaranteed or endorsed by the publisher.

Copyright $\odot 2021$ Schroeer, Voss, Jung-Sievers and Coenen. This is an open-access article distributed under the terms of the Creative Commons Attribution License (CC $B Y)$. The use, distribution or reproduction in other forums is permitted, provided the original author(s) and the copyright owner(s) are credited and that the original publication in this journal is cited, in accordance with accepted academic practice. No use, distribution or reproduction is permitted which does not comply with these terms. 